\title{
The effect of conflict at work on well-being: Depressive symptoms as a vulnerability factor
}

\author{
Laurenz L. Meier ${ }^{\mathrm{a}, \mathrm{b} *}$, Norbert K. Semmer ${ }^{\mathrm{c}}$ and Sven Gross ${ }^{\mathrm{c}}$ \\ ${ }^{a}$ Department of Psychology, University of South Florida, Tampa, FL, USA; ${ }^{b}$ Department of \\ Psychology, University of Fribourg, Fribourg, Switzerland; ' Department of Psychology, \\ University of Bern, Bern, Switzerland
}

(Received 8 May 2012; final version accepted 16 August 2013)

\begin{abstract}
In occupational health research, aspects of psychological well-being, including depressive symptoms, have mainly been considered as an outcome. In this research, we examined the role of depressive symptoms as a moderator in the relationship between interpersonal conflict at work and psychological and physical well-being. We assumed that people with relatively high levels of chronic depressive symptoms react particularly strongly to conflict. We tested our hypotheses with a cross-sectional study $(N=218)$ and with a diary study over two weeks $(N=127)$. Both studies were conducted in Switzerland. The results of both studies showed that conflict was related to impaired psychological well-being (depressive mood and job satisfaction) and physical well-being (somatic complaints). In line with our assumption, this effect was particularly strong for people with high levels of chronic depressive symptoms. Thus, our findings suggest that conflict may lead to depressive symptoms, which make people even more vulnerable to conflicts, indicating a vicious circle with high psychological and economic costs.
\end{abstract}

Keywords: conflict; depressive symptoms; well-being; job satisfaction; somatic complaints; moderation; work-related stress

\section{Introduction}

Previous research has clearly indicated that adverse work conditions are positively related to depressive symptoms (Bonde, 2008; Tennant, 2001). Prospective studies suggest that work stressors such as conflict are likely to increase depressive symptoms (e.g. Dormann \& Zapf, 1999), but that depressive symptoms may also lead to an increase in experienced work stressors (e.g. Finne, Knardahl, \& Lau, 2011). Thus, depressive symptoms can be considered both as a consequence and an antecedent of work stressors, pointing to a loss spiral. Hence, they may play a role in the pathogenesis of more severe psychological disorders such as major depression. However, depressive symptoms may be important beyond being a potential predictor and outcome. They may act as a moderator by aggravating the negative impact of work stressors on psychological and physical well-being, which would further strengthen the loss spiral. However, previous

*Corresponding author. Email: laurenz.meier@unifr.ch 
research has focused on depressive symptoms as outcome or predictor, but neglected its potential role as a moderator in the relationship between stressor and strain. In this paper, we present two studies that address this issue and help to extend our knowledge about the role of depressive symptoms in work stress. We focused on conflict as work stressor because conflict has been considered as particularly stressful (e.g. Bolger, DeLongis, Kessler, \& Schilling, 1989) and because people with high levels of depressive symptoms are expected to be particularly vulnerable to such a social stressor.

\section{Conflict at work and well-being}

Interpersonal conflicts in the workplace may occur in diverse forms, ranging from minor disagreements between co-workers and supervisor to assaults on others, and they may be overt or covert (see Spector \& Jex, 1998). Conflicts may refer to disagreements that are related to feelings of animosity (relationship conflict) or to disagreements regarding the best way to accomplish a task (task conflict) (e.g. Jehn, 1995). Conflicts are often associated with the experience of disrespect and interpersonal rejection; this is particularly true for relationship-related conflict (see De Dreu \& Gelfand, 2008; Meier, Gross, Spector, \& Semmer, 2013). Events involving interpersonal rejection are especially aversive because they undermine the fundamental need to belong to significant others and to maintain good interpersonal relationships (Baumeister \& Leary, 1995).

Interpersonal conflict at work has been linked to various indicators of well-being, such as depressive symptoms, job satisfaction and somatic symptoms (e.g. Spector \& Bruk-Lee, 2008). Most of this research is based on cross-sectional data. However, there are a few studies that examined associations between conflicts and well-being across time. With regard to rather long time lags (i.e. several months), Dormann and Zapf (1999) found that interpersonal conflict was prospectively related to depressive symptoms, at least when social support was low. With regard to very short time lags (i.e. hours), Ilies, Johnson, Judge, and Keeney (2011) and Meier et al. (2013) found that interpersonal conflict had short-term effects on negative mood. Thus, it is reasonable to assume that both chronic conflict and daily conflict episodes may impair well-being.

\section{The moderating role of depressive symptoms}

As mentioned above, depressive symptoms have been almost exclusively considered as an outcome variable, and research on conflict (Dormann \& Zapf, 1999) and related stressors such as a bad team climate (Ylipaavalniemi et al., 2005) found lagged effects on depressive symptoms. In our research, however, we assumed not only that depressive symptoms are the result of conflicts, but also that people with depressive symptoms are more vulnerable to conflict (i.e. it strengthens the relationship between conflicts and wellbeing). In line with taxometric analyses showing that depressive symptoms are best conceptualized as a continuous construct (e.g. Prisciandaro \& Roberts, 2005; Ruscio \& Ruscio, 2000), we use the term depressive symptoms to denote a continuous variable (i.e. individual differences in depressive symptoms) rather than a clinical category such as major depressive disorder. The dimensional nature of depressive symptoms implies that clinically depressed individuals are to be found only in the high range of depressive 
symptoms (see Baldwin \& Shean, 2006), and that people who are not clinically depressed (such as those in our sample) can still show quite some variance in depressive symptoms.

The theoretical rationale of an increased reactivity of people with a high level of depressive symptoms to conflicts is based on appraisal theory (Lazarus, 1991; Ellsworth \& Scherer, 2003). According to this theory, people appraise (i) whether a situation threatens important needs and goals and hence is relevant for their well-being (primary appraisal) and (ii) whether efforts to cope with the situation might change the situation (secondary appraisal). Regarding primary appraisal, people with high levels of depressive symptoms have been found to be more dependent on others, having insecure feelings of belonging, fears of abandonment, and feelings of weakness and helplessness (Blatt, Quinlan, Chevron, McDonald, \& Zuroff, 1982). Thus, negative situations that threaten the need to belong, such as conflicts (see above), are expected to be appraised as particularly threatening by people with relatively high depressive symptoms; in line with this, people with high levels of depressive symptoms react particularly strongly to interpersonal rejection (Nezlek, Kowalski, Leary, Blevins, \& Holgate, 1997, Experiment 1).

More generally, various models suggest that affect influences how situations and persons are judged (see Forgas, 1992). For example, people in a sad mood (which is more typical for people with high, as opposed to low, depressive symptoms) attribute conflict more to internal, stable and global causes (Forgas, 1994), which, in turn, is likely to affect the perceived intensity of the conflict. Moreover, people in a sad mood identified more negative behaviour in videotaped interactions than people in a positive mood, and they recalled more details about difficult interactions later on (Forgas, Bower, \& Krantz, 1984). Thus, mood-dependent effects have been found for attention as well as for memory, and these are likely to affect how conflicts are appraised.

Regarding secondary appraisal, a large body of research indicates that depressive symptoms are related to deficiencies in interpersonal competences such as conflict management (see Segrin, 2000). Thus, depressive symptoms predicted lower social skills in a non-clinical sample (Cole \& Milstead, 1989). Coyne (1976) suggested that depressed people interact with others in a manner that is experienced as aversive by the interaction partners, for example, because the content of the conversation is negatively toned and self-referential. Furthermore, experimental laboratory studies suggest that people in a depressed mood tend to show more dysfunctional conflict behaviour (e.g. less cooperation, more competition) than people in a neutral mood (Forgas, 1998). Thus, people with high levels of depressive symptoms are likely to cope with conflicts less efficiently, which may cause conflicts to escalate. These negative effects may be further intensified by the fact that people with high levels of depressive symptoms are prone to ruminate about negative events and current feelings (Moulds, Kandris, Starr, \& Wong, 2007; Nolen-Hoeksema, Morrow, \& Fredrickson, 1993; Teasdale, 1983). Ruminative thoughts imply a continuing focus on stress appraisals, prolonging stress-related affective and physiological activations, and thus the duration of the negative effects of work stressors (see Brosschot, Gerin, \& Thayer, 2006; Meurs \& Perrewé, 2011). In line with this argument, the role of rumination has been stressed in the development of both depression (e.g. Nolen-Hoeksema, 1990) and somatic disease (e.g. Brosschot et al., 2006). All this suggests that people with high levels of depressive symptoms should react particularly strongly to conflicts at work. 


\section{The present study}

Based on the considerations presented above, we suggest the following hypotheses:

Hypothesis 1: Interpersonal conflict will be negatively related to well-being.

Hypothesis 2: The effect of interpersonal conflict on well-being will be particularly strong among people with high levels of depressive symptoms.

Two considerations guided the selection of well-being indicators for our research. First, we wanted to include indicators of both psychological and physical well-being. Second, we wanted to ensure compatibility with existing research on conflict, and on stress more generally. With regard to psychological well-being, we followed the theory of subjective well-being by Diener, Oishi, and Lucas (2003), which includes affective and cognitive components. Furthermore, following Warr's (e.g. 1999, 2005) distinction between context-free and job-related well-being, we focused on job-related well-being and included job-related depressive mood as an indicator of the affective, and job satisfaction as indicator of the cognitive component. With regard to physical well-being, we used somatic complaints (Schat, Kelloway, \& Desmarais, 2005) as an indicator. Importantly, all three outcomes have often been used as well-being indicators in previous research on conflict (e.g. Spector \& Jex, 1998).

One may wonder why we chose depressive mood as an outcome while testing chronic depressive symptoms as moderator, as the two measures are conceptually very similar. However, it is absolutely conceivable that even the very same variable is an outcome of specific experiences (depressive tendencies are strengthened by conflict; cf. Dormann \& Zapf, 1999) and a moderator at the same time (depressive tendencies are strengthened more for people who already have such tendencies to a relatively high degree, as their appraisal is particularly negative and their coping skills particularly poor). Note, however, that the outcome and the moderator were conceptualized differently in the present research.

In the first (cross-sectional) study, we focused on job-related depressive mood as outcome. Referring to one's work, job-related depressive mood is context-specific (Van Katwyk, Fox, Spector, \& Kelloway, 2000); this distinguishes it from chronic depressive symptoms, which refer to a global negative feeling with self-destructive thoughts (see Stoner \& Perrewé, 2006). When examining the effects of job-related stress on job-related depressive symptoms, it seems important to control for general depressive symptoms so it can be ruled out that effects found are due to a more general personal characteristic. Therefore, we examined whether interpersonal conflict was related to job-related depressive mood over and above the effect of general depressive symptoms, and if this effect was stronger for people high in general depressive symptoms, the latter referring to our discussion about the moderating role of depressive symptoms. Controlling for general depressive symptoms renders the test of both hypotheses rather rigorous, similar to controlling for negative affectivity in stress research (see Spector, Zapf, Chen, \& Frese, 2000). In the second (diary) study, we focused on state depressive mood, assessed while people were at work. Thus, we examined if daily fluctuations in conflict have an effect on momentary depressive mood that cannot be explained by inter-individual differences in general depressive symptoms; again, we additionally tested if this effect was stronger for people high in general depressive symptoms. 
By using these two different study designs, we were able to test the effect of conflict on well-being both at the inter-individual and at the intra-individual level. Most stress research tests if people experiencing more stressors (e.g. conflict) than other people will have a lower well-being than people experiencing fewer stressors, thus assessing between-person effects. In contrast, studies on intra-individual effects test if a person experiencing more stressors than usual will have lower well-being than usual, thus assessing within-person effects. Thus, the two analyses address related but distinct questions (see also Cervone, 2005).

\section{Method}

\section{Method overview}

To test our hypotheses, we conducted a cross-sectional and a diary study in Switzerland. In both studies, participants were recruited by research assistants via direct or indirect (e.g. email, phone) contact among their acquaintances. When interest in participating was expressed, the research assistants met the participants individually, explained the procedure and distributed the survey. However, the participants were not told which specific work condition and aspect of well-being would be measured. In the crosssectional study, participants returned the survey with a prepaid envelope to the first author. In the diary study, the students kept contact (on average every other day) with the participants to answer any questions and to sustain the participants' commitment during data collection. Participants regularly returned their survey to the research assistants in sealed envelopes. As a compensation for the participants' time and as an incentive for their participation, participants were offered written individual feedback by the first author about their work situation and their well-being after the study was finished. If the results were critical, they were discussed with the participant in detail, advice was given on how to cope with work stress, and they were given web links to additional sources of help as well as the first author's contact information.

\section{Study 1: Cross-sectional study}

\section{Participants and procedure}

The sample consisted of 218 employees, holding a variety of jobs, such as shop assistant $(30 \%)$, nurse $(12 \%)$, administrative staff $(12 \%)$ or software engineer $(5 \%)$, plus various other occupations (mainly professionals such as lawyers and consultants). Blue-collar workers, such as cooks, were relatively rare $(9 \%)$. Mean age was 35.7 years $(S D=11.4$; range $=17-64)$. A slight majority (52\%) was female. Forty-two per cent had completed regular school (9 years) or an apprenticeship, 35\% had completed college and $23 \%$ had a university degree. All participants worked at least $50 \%$ of a full-time equivalent (FTE). Mean organizational tenure was 6.1 years $(S D=6.9$; range $=.1-35.0$ years $)$.

\section{Measures}

Conflict at work. Conflict was measured with the relationship conflict scale by Jehn (1995). The scale consisted of four items (e.g. "How often is there tension among 
members in your work unit?"). The response format ranged from very rarely/never (1) to very often/all the time (5). Internal consistency was $\alpha=.91$.

General depressive symptoms. Chronic depressive symptoms were assessed with a short version of German version of the Center for Epidemiologic Studies Depression Scale (CES-D; Radloff, 1977; German version by Hautzinger \& Bailer, 1993). The CES-D is a frequently employed measure for assessing depressive symptoms in nonclinical, subclinical and clinical populations (Eaton, Smith, Ybarra, Muntaner, \& Tien, 2004). Participants were instructed to assess how frequently they had experienced each symptom within the preceding 30 days (e.g. "I felt depressed"). The scale consisted of 15 items. The answering format ranged from seldom/not at all (1) to mostly (4). Internal consistency was $\alpha=.93$.

Job-related depressive mood. Job-related depressive mood was assessed with five items from the Job-Related Affective Well-Being Scale (JAWS) by Van Katwyk et al. (2000) that focuses on negative evaluation and low arousal (e.g. depressed, gloomy). Participants had to indicate how often their job made them feel each emotion in the last 30 days. Response choice ranged from never (1) to extremely often/always (5). Internal consistency was $\alpha=.76$.

Job satisfaction. Job satisfaction was assessed with a scale by Baillod and Semmer (1994). The scale has four items, one of which is a Kunin Faces Scale asking "How satisfied are you in general with your work?". It ranges from extremely dissatisfied (1) to extremely satisfied (7). The other items ask participants to indicate how often they had specific thoughts about their work (e.g. "I hope my job situation will always remain as good as it is now"), ranging from never (1) to always (7). Internal consistency was $\alpha=.81$.

Somatic complaints. Somatic complaints were assessed with seven items about headaches and gastrointestinal problems from the Physical Health Questionnaire (PHQ) by Schat et al. (2005). Participants indicated how frequently they had experienced each symptom within the preceding 30 days on a Likert scale ranging from never (1) to very often/all the time (7). The sum of these items is a meaningful indicator of somatic complaints; however, it does not reflect a single underlying construct (see Schat et al., 2005). Therefore, internal consistency is not a meaningful measure for this scale (see Spector \& Jex, 1998).

\section{Confirmatory factor analyses}

To ensure that our predictors and outcomes represented empirically distinguishable constructs, we conducted confirmatory factor analyses. Specifically, we examined whether a five-factor model was better than a one-factor model. The proposed five-factor model, containing conflict, general depressive symptoms, job-related depressive mood, somatic complaints and job satisfaction, had a good fit $\left(\chi^{2}(125)=202.40\right.$, Comparative Fit Index $(\mathrm{CFI})=.97$, Tucker-Lewis Index $(\mathrm{TLI})=.96$, root-mean-square error of approximation $($ RMSEA $)=.06$, standardized root mean squared residual $($ SRMR $)=.06)$, which was significantly better than the fit for the one-factor model $\left(\chi^{2}(135)=1167.31, \mathrm{CFI}=.56\right.$, TLI 
$\left.=.50, \mathrm{RMSEA}=.19, \mathrm{SRMR}=.16 ; \Delta \chi^{2}(10)=964.91, p<.05\right)$ and a four-factor model that combined chronic depressive symptoms and job-related depressive mood into a single factor $\left(\chi^{2}(129)=306.54\right.$, CFI $=.92$, TLI $=.91$, RMSEA $=.08$, SRMR $=.07 ; \Delta \chi^{2}(4)=$ $104.09, p<.05)$. Additionally, we examined whether chronic depressive symptoms and job-related depressive mood were distinct constructs. A two-factor model had a good model fit $\left(\chi^{2}(19)=43.40, \mathrm{CFI}=.98, \mathrm{TLI}=.97, \mathrm{RMSEA}=.08\right.$, SRMR $\left.=.04\right)$, which was significantly better than the fit of the one-factor model $\left(\chi^{2}(20)=131.16, \mathrm{CFI}=.90, \mathrm{TLI}=\right.$ $.86, \mathrm{RMSEA}=.16$, SRMR $\left.=.07 ; \Delta \chi^{2}(1)=87.76, p<.05\right)$.

\section{Control variables}

Previous research has shown that women are more likely than men to experience depression (Nolen-Hoeksema, 1990), which may be the result of women's greater reactivity to stressors (see Nolen-Hoeksema, 2001) or of women's more frequent experience of interpersonal conflicts (e.g. Narayanan, Menon, \& Spector, 1999). Furthermore, age is related to depression (e.g. Burke, Burke, Regier, \& Rae, 1990); research suggests that older people are more likely to manage conflicts through problem solving (Van Lange, Otten, De Bruin, \& Joireman, 1997), and to use more adaptive emotion regulation strategies (e.g. reappraisal; John \& Gross, 2004) than younger people. Therefore, to test if the proposed interaction effect of conflicts and depressive symptoms was spurious, we controlled for gender and age.

\section{Study 2: Diary study}

\section{Participants and procedure}

The sample consisted of 127 employees holding a variety of jobs, such as administrative staff $(22 \%)$, computer specialist $(13 \%)$, social worker $(7 \%)$, or engineer $(6 \%)$, plus various other occupations (mainly professionals such as architects and consultants). Blue-collar workers, such as toolmakers were relatively rare $(9 \%)$. Mean age was 35.6 years $(S D=11.5$; range $=16-59$ years). A slight majority (55\%) was male. Thirty-two per cent had completed regular school (9 years) or an apprenticeship, $44 \%$ had completed college and $24 \%$ had a university degree. All of the participants worked at least $50 \%$ of a FTE. Organizational tenure ranged from 0.1 to 35.0 years; average tenure was 5.1 years $(S D=6.7)$.

Before the diary study started, participants completed a general questionnaire assessing their chronic level of depressive symptoms and demographic variables. At the beginning of the following week, participants began completing daily surveys for two weeks, including the weekend. To reduce the contamination of the predictor (conflict) by the outcome, we assessed the predictor and the outcome separately (see Ohly, Sonnentag, Niessen, \& Zapf, 2010).. In the afternoon, approximately 1.5 hours before the end of work, participants filled out a questionnaire about positive and negative events at work (e. g. conflict). At the end of work, they reported their momentary well-being (i.e. depressive mood, job satisfaction, somatic complaints). On non-working days, participants were asked to omit the afternoon survey (assessing work events), but to fill out the end-of-work survey (assessing well-being).

Of the 127 participants in the initial sample, 58 did not report any working day with conflicts. Having no intra-individual variance in the predictor (i.e. conflict), these 58 participants were removed from the data set, yielding a final sample of 
69 participants. Overall, they completed 603 afternoon surveys, corresponding to a mean of $8.6(S D=1.8)$ per participant, and 916 end-of-work surveys, corresponding to 13.3 $(S D=1.4)$ per participant. The participants who were excluded did not differ from the remaining ones with regard to gender, age and tenure. However, they reported fewer chronic depressive symptoms than those who were included $(d=.58, p<.05)$. We see three possible reasons for this difference. First, the participants included experienced more conflicts, which can cause depression (see Hypothesis 1). Second, employees with higher levels of depressive symptoms may provoke more conflicts (e.g. Cummings, Hayes, Laurenceau, \& Cohen, 2010). Third, employees with higher levels of depressive symptoms may perceive situations as more conflict-ridden (Beck, 1987). Note, however, that we centred conflict (a Level 1 variable) about the individual mean (group mean centring), which implies that all between-person variance was removed. Thus, the results cannot be interpreted in terms of stable differences between persons, and the coefficients for conflict reflect the effect of a person having many or few conflicts relative to his or her own mean for that variable across days. Nevertheless, we ran additional analyses with the complete sample $(N=127)$; results were almost identical (i.e. significant main effects and cross-level interaction effects of very similar size).

\section{Measures}

Conflict at work. Conflict at work was measured with a single item in the afternoon survey ("Today, I had a conflict at work"). The response format ranged from completely disagree (1) to completely agree (4).

State depressive mood. At the end of work, daily depressive mood was measured with a shortened five-item version of the CES-D (Radloff, 1977; see Study 1). We adapted the wording to refer to how participants felt during that day ("Today, I felt I could not shake off the blues"). The response format ranged from completely disagree (1) to completely agree (5). The reliability of the scale, calculated according to Nezlek (2007), was .73.

State job satisfaction. At the end of work, job satisfaction was measured using a single item ("How satisfied are you with your work at the moment?") with a faces scale (Kunin, 1955), consisting of seven faces, ranging from extremely dissatisfied (1) to extremely satisfied (7).

State somatic complaints. At the end of work, somatic complaints were assessed with four items from Mohr (1986), assessing headaches and gastrointestinal problems with two items each. Participants indicated how they felt at the moment (e.g. "At the moment, I have a headache"). The response format ranged from completely disagree (1) to completely agree (5). As noted above, internal consistency is not an appropriate indicator of reliability for this scale.

Chronic depressive symptoms. We used the same measure (CES-D; Radloff, 1977) as in Study 1 . Internal consistency was .86 . 
Control variables. As in Study 1, we controlled for gender and age in our analyses.

\section{Results}

\section{Cross-sectional study (Study 1)}

Means, standard deviations and zero-order correlations are shown in Table 1. We conducted hierarchical regression analyses to test our hypotheses, centring predictor variables around their mean to facilitate the interpretation of main effects in models containing interaction terms (Aiken \& West, 1991). We entered conflict and depressive symptoms in the first step, and their interaction in the second step. To examine the impact of the control variables, we entered age and gender in the third step, and the interaction of conflict and age, as well as the interaction of conflict and gender in the fourth step. However, the inclusion of age and gender did not alter the results. Therefore, we dropped the control variables from the final analyses. For directional hypotheses one-tailed tests were used.

Results of the hierarchical regression analyses are displayed in Table 2. In line with Hypothesis 1, conflict was related positively to job-related depressive mood and negatively to job satisfaction. Unexpectedly, conflict was not related to somatic complaints when we controlled for depressive symptoms. Note, however, that the bivariate correlation between conflict and somatic complaints was significant (see Table 1). Moreover, as postulated in Hypothesis 2, depressive symptoms had a strengthening effect on the slope

Table 1. Descriptive statistics and zero-order correlations of study variables in Study 1.

\begin{tabular}{lrrrrrrrr}
\hline Variables & $M$ & $S D$ & 1 & 2 & 3 & 4 & 5 & 6 \\
\hline 1. Gender $^{\mathrm{a}}$ & .48 & - & - & & & & & \\
2. Age & 35.67 & 11.38 & .11 & - & & & & \\
3. Conflict & 2.26 & 0.81 & -.01 & .04 & - & & & \\
4. Chronic depressive & 1.67 & 0.54 & .05 & -.11 & $.19^{*}$ & - & & \\
$\quad$ symptoms & & & & & & & & \\
5. Job-related depressive mood & 2.32 & 0.69 & -.01 & $-.20^{*}$ & $.31^{*}$ & $.71^{*}$ & - & \\
6. Job satisfaction & 4.44 & 1.23 & -.05 & .10 & $-.32^{*}$ & $-.39^{*}$ & $-.51^{*}$ & - \\
7. Somatic complaints & 2.05 & 0.96 & $-.21^{*}$ & $-.16^{*}$ & $.14^{*}$ & $.51^{*}$ & $-.49^{*}$ & $-.33^{*}$ \\
\hline
\end{tabular}

Note: $N=218 .{ }^{\mathrm{a}} 0=$ female, $1=$ male. ${ }^{*} p<.05$.

Table 2. Hierarchical multiple regression analyses predicting job-related depressive mood, job satisfaction and somatic complaints (Study 1).

\begin{tabular}{|c|c|c|c|c|c|c|}
\hline \multirow[b]{2}{*}{ Predictor } & \multicolumn{2}{|c|}{$\begin{array}{c}\text { Job-related } \\
\text { depressive mood }\end{array}$} & \multicolumn{2}{|c|}{$\begin{array}{c}\text { Job } \\
\text { satisfaction }\end{array}$} & \multicolumn{2}{|c|}{$\begin{array}{l}\text { Somatic } \\
\text { complaints }\end{array}$} \\
\hline & $\Delta R^{2}$ & $\beta$ & $\Delta R^{2}$ & $\beta$ & $\Delta R^{2}$ & $\beta$ \\
\hline Step 1 & $.53 *$ & & $.22 *$ & & $.26^{*}$ & \\
\hline Conflict & & $.17^{*}$ & & $-.26^{*}$ & & .04 \\
\hline Chronic depressive symptoms & & $.67 *$ & & $-.34 *$ & & $.50 *$ \\
\hline Step 2 & $.01^{*}$ & & $.03 *$ & & $.02 *$ & \\
\hline Conflict $\times$ Depressive symptoms & & $.10^{*}$ & & $-.18^{*}$ & & $.13^{*}$ \\
\hline
\end{tabular}

Note: $N=218 .{ }^{*} p<.05$. 


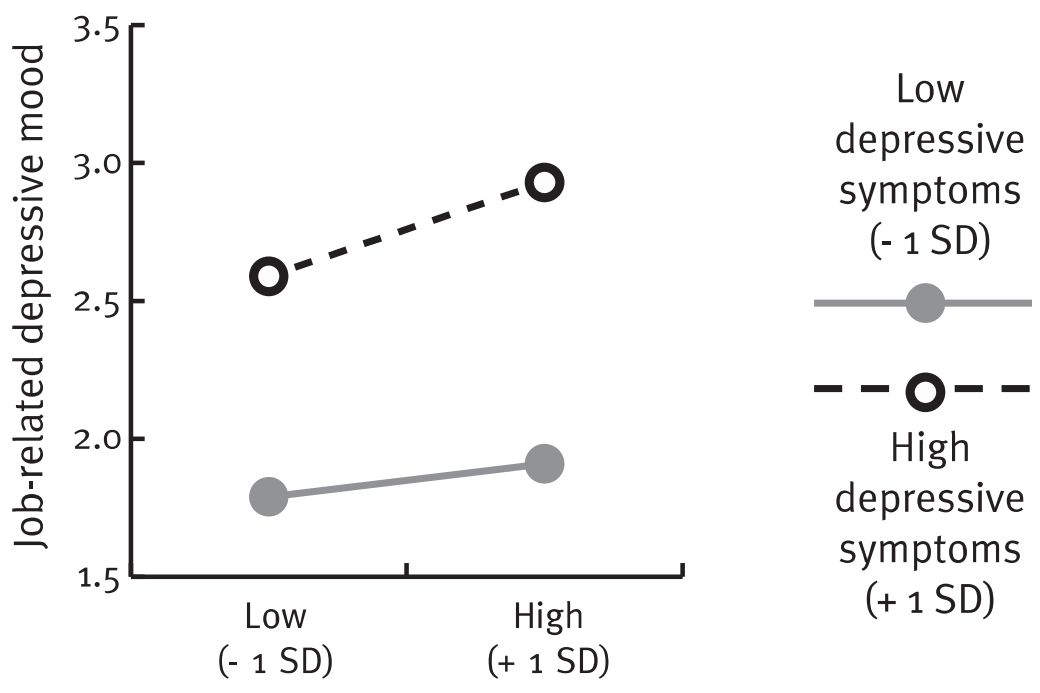

\section{Conflict}

Figure 1. Interaction between conflict and chronic depressive symptoms predicting impaired wellbeing.

of conflict for depressive mood, job satisfaction and somatic complaints. For a more specific test of our hypotheses, we conducted simple slope tests for values $1 S D$ above and below the mean, as suggested by Aiken and West (1991). In line with our assumption, conflict was related to job-related depressive $\operatorname{mood}(B=.21, p<.01)$, job satisfaction $(B=$ $-.58, p<.01)$, and somatic complaints $(B=.16, p<.05)$ only among people with relatively high levels of depressive symptoms, but not among people with low levels of depressive symptoms $(B=.07, \mathrm{~B}=-.12$, and $B=-.10$, respectively, all $n s)$. Figure 1 illustrates these results for job-related depressive mood. The graphs for the other outcomes, not shown for reasons of space, were very similar and can be obtained from the first author.

\section{Diary study (Study 2)}

\section{Data analysis}

Because the daily data were nested within persons, we analyzed them with a multi-level random coefficient model, using the program HLM 6.06 (Raudenbush, Bryk, Cheong, \& Congdon, 2004). We examined the within-person relations between conflict at work and well-being. To model the change in each outcome, we controlled for its baseline level by including the previous assessment as a predictor (i.e. well-being at the previous day). Level 1 predictors (conflict and baseline measures of the outcomes) were group mean-centred.

Of special interest was whether chronic depressive symptoms had an influence on the effect of daily conflict on state well-being. The measure of chronic depressive symptoms was centred around the grand mean to predict (i) the Level 1 intercept (i.e. the influence of chronic depressive symptoms on state well-being) and (ii) the Level 1 slope of conflict (i.e. the moderating effect of chronic depressive symptoms on the effect of conflict on state well-being). Furthermore, gender (uncentred), and age (grand-mean centred) were entered as covariates. However, with one exception that is noted, the inclusion of gender 
Table 3. Descriptive statistics and zero-order correlations of study variables in Study 2.

\begin{tabular}{lrrrrrrr}
\hline Variables & $N$ & $M$ & $S D$ & ICC & 1 & 2 & 3 \\
\hline Chronic measures (Level 2) & & & & & & & \\
1. Gender & 69 & 0.49 & - & - & - & - & - \\
2. Age & 69 & 35.41 & 10.85 & - & .12 & - & - \\
3. Chronic depressive symptoms & 69 & 1.67 & 0.41 & - & .07 & .11 & - \\
Daily measures (Level 1) & & & & & & & \\
1. Conflict & 603 & 1.45 & 0.87 & $.04^{\mathrm{b}}$ & - & & \\
2. Depressive mood & 916 & 1.48 & 0.66 & .38 & $.19^{*}$ & - & \\
3. Job satisfaction & 915 & 5.19 & 1.15 & .53 & $-.13^{*}$ & $-.37^{*}$ & - \\
4. Somatic complaints & 906 & 1.21 & 0.41 & .47 & .05 & $.32^{*}$ & $-.11^{*}$ \\
\hline
\end{tabular}

Note: Within-person (Level 1) correlations were calculated using the Mplus program (Muthén \& Muthén, 2010). ICC $=$ Intraclass correlation (proportion of the between-person variance compared with the total variance). ${ }^{\mathrm{a}} 0=$ female, $1=$ male. ${ }^{\mathrm{b}} \mathrm{ICC}$ of sample with unrestricted between-person variance in conflict (see Method section) is .15 .

${ }^{*} p<.05$.

and age did not alter the results. Therefore, the control variables were dropped from the final analyses. We used the restricted maximum-likelihood procedure in HLM to estimate the fixed and random parameters and the robust standard errors for the significance tests (see Hox, 2010). For directional hypotheses one-tailed tests were used.

\section{Findings}

Means, standard deviations, intra class correlations and zero-order correlations for the diary study are shown in Table 3. Results of the multilevel analyses are displayed in Table 4. In line with Hypothesis 1, conflict was positively related to state depressive mood and to state somatic complaints, and negatively related to state job satisfaction. Moreover, as postulated in Hypothesis 2, chronic depressive symptoms had a strengthening effect on the slope of conflict for all three outcome measures. For a more specific test of our hypotheses, we conducted simple slope tests using a tool by Preacher, Curran, and Bauer (2006). In line with our assumption, and replicating the findings from Study 1, conflict was related to state depressive mood $(B=.28, p<.01)$, state job satisfaction $(B=-.34, p<.01)$, and state somatic complaints $(B=.06, p<.05)$ only among people with high, but not among people with low levels of chronic depressive symptoms $(B=.07, p<.05, B=-.08, n s$ and $B=.01$, $n s$, respectively). The result pattern was very similar to the one shown in Figure 1; graphs for these analyses can be obtained from the first author.

\section{Discussion}

This research showed that depressive symptoms strengthened the negative effect of conflict at work on psychological and physical well-being. More specifically, conflict was particularly strongly linked to job satisfaction, depressive mood and somatic complaints among people with high levels of depressive symptoms. This effect was found in both a cross-sectional and a diary study, and thus held for chronic conflict as well as for daily conflict, and at the between-person level as well as at the within-person level. 
Table 4. Multilevel analyses predicting depressive mood, job satisfaction and somatic complaints (Study 2).

\begin{tabular}{|c|c|c|c|c|c|c|}
\hline & \multicolumn{2}{|c|}{ Depressive mood } & \multicolumn{2}{|c|}{ Job satisfaction } & \multicolumn{2}{|c|}{ Somatic complaints } \\
\hline & $B$ & $S E B$ & $B$ & $S E B$ & $B$ & $S E B$ \\
\hline Intercept & $1.47^{*}$ & 0.04 & $5.09 *$ & 0.09 & $1.19^{*}$ & 0.03 \\
\hline \multicolumn{7}{|c|}{ Effects of Level 1 variables } \\
\hline Conflict & $0.18^{*}$ & 0.03 & $-0.22 *$ & 0.07 & $0.04 *$ & 0.02 \\
\hline Autocorrelation & 0.07 & 0.05 & $0.09 *$ & 0.05 & 0.08 & 0.06 \\
\hline \multicolumn{7}{|c|}{ Effects of chronic depressive symptoms on: } \\
\hline Intercept & $0.67 *$ & 0.08 & $-0.94^{*}$ & 0.20 & $0.25 *$ & 0.07 \\
\hline Slope of conflict & $0.25 *$ & 0.06 & $-0.32 *$ & 0.16 & $0.07^{\dagger \mathrm{a}}$ & 0.05 \\
\hline
\end{tabular}

Note: ${ }^{a}$ In the model with age and sex as control variables, the effect was significant $(B=.09, p<.05)$. ${ }^{\dagger} p<.10 .{ }^{*} p<.05$.

The fact that conflict was negatively related to well-being is in line with previous research (see Spector \& Bruk-Lee, 2008). The main contribution of the present study relates to the role of depressive symptoms as a moderator, which extends previous research. In line with our assumption, employees with higher levels of depressive symptoms reacted particularly strongly to conflict. These findings point to a potentially dangerous vicious circle: conflicts at work induce depressive mood, which in the long run makes people even more vulnerable to conflicts. This might be a central mechanism through which the experience of daily hassles such as conflicts, even if minor, may lead to more severe psychological problems (e.g. clinical depression), which cause suffering and impaired job performance (Adler et al., 2006), and can have economic cost implications (e.g. Greenberg et al., 2003; McTernan, Dollard, \& LaMontagne, 2013). Note that depressive symptoms strengthened the effect of conflict not only on psychological but also on physical health. Thus, depressive symptoms are a vulnerability factor that is likely to undermine both psychological and physical resources. In a more general sense, such mechanisms could produce the "loss spirals" postulated by conservation of resources theory (Hobfoll, 2001).

Studies focusing on psychological well-being not only as an outcome but also as a moderator in the stressor-strain relationship are rare. The few studies indicating that wellbeing is a vulnerability factor have focused on physical well-being. Mulders, Meijman, O'Hanlon, and Mulder (1982) showed that bus drivers with high sickness frequency had stronger neuro-endocrine reactions at work than those with low sickness frequency. Similarly, Elfering, Grebner, Gerber, and Semmer (2008) showed that work stressors were particularly strongly related to norepinephrine excretion among people with high levels of musculoskeletal pain. Kottwitz et al. (2013) showed that perceived health moderated the association between illegitimate tasks and cortisol. Research on impaired psychological well-being as a vulnerability factor, however, is widely lacking, and we hope that the present study inspires scholars to consider (impaired) well-being not only as an outcome but also as an important part of the stress process. In terms of conservation of resources theory (e.g. Hobfoll, 2001), increased levels of depressive symptoms imply a loss of resources, which, in turn, increases vulnerability to further negative events. 
In both studies, our outcomes included a variable that had a special relationship to our moderator, that is, depressive symptoms. Job-related depressive mood (Study 1) concerns a variable that is akin to depressive symptoms, albeit in a much more specific and circumscribed way; being tied more specifically to working conditions, it also is likely to be more malleable than general depressive symptoms. In Study 2, state depressive mood was assessed, which again is more specific and malleable than depressive symptoms in general. Such more specific well-being indicators are likely to be more reactive to working conditions than general depressive symptoms. In line with emotion-centred process models of job stress (e.g. Spector \& Bruk-Lee, 2008) that propose that stressors such as conflict trigger negative emotions which then lead to more chronic strain, it is likely that (job-related and state) depressive mood feeds back into chronic depressive symptoms if it occurs frequently over an extended period. Such specific and more focused indicators of depressive mood may, therefore, be a mediator in the process through which conflict (and other stressors) may, in the long run, lead to yet higher depressive symptoms.

\section{Practical implications}

With regard to practical implications, our results highlight the importance of conditions at work. The present study focused on the interplay of individual differences and social conditions at work. Individual differences are traditionally in the focus of selection procedures, because they correlate with performance (e.g. Barrick, Mount, \& Judge, 2001) or because they are related to the ability to cope with stressful conditions at work (as in the present study). However, focusing exclusively on selection would ignore the possibility that depressive symptoms may partly be an effect of working conditions that are characterized by conflict and interpersonal tensions (Dormann \& Zapf, 1999). Our finding that the main effects explained more variance than the interaction effects suggests that it may be most promising to focus on working conditions in terms of minimizing conflict (e.g. foster trust and support and minimize tensions, see De Dreu \& Van de Vliert, 1997; Folger, Poole, \& Stutman, 2001). Additionally, stress reduction programmes based on redesigning jobs with lower job demands, and better conditions of cooperation and communication (e.g. Kawakami, Araki, Kawashima, Masumoto, \& Hayashi, 1997) may be worth considering. Finally, training in coping skills (e.g. van der Klink, Blonk, Schene, \& van Dijk, 2001) seems to be promising in reducing depressive symptoms. Furthermore, supervisors might be trained in recognizing depressive symptoms and in interpreting poor conflict behaviour as a sign of poor coping skills rather than in terms of hostile intentions, and they might be trained in fostering ways of dealing with conflicts that minimize threats to the sense of being accepted.

Certain limitations in the present study should be acknowledged. First, the idea of a vicious circle should be tested with longitudinal studies; they could clarify how long it takes until conflicts impact depressive symptoms, and they should try to replicate the moderating effect of depressive symptoms. They should also investigate the effect of more circumscribed and focused indicators of depressive symptoms, such as state depressive mood and job-related depressive mood, on the long-term development of depressive symptoms in a more general sense. Moreover, longitudinal studies would also shed further light on the role of depressive symptoms in predicting conflict. Researchers have proposed that conflict may be not only the cause but also the result of impaired well- 
being such as chronic depressive symptoms (e.g. De Dreu \& Beersma, 2005). Recent findings from related research about justice (Lang, Bliese, Lang, \& Adler, 2011) and bullying (Finne et al., 2011) suggests that chronic depressive symptoms may also lead to the experience of poorer work conditions (more injustice, more bullying). We found no support for such effects in Study 2; however, future research may use shorter timeframes (e.g. depressive mood in the morning and conflict during the same day) as well as longer ones (e.g. chronic depressive symptoms and chronic conflict over several months). It is important to note, however, that such reversed effects are not the same as the moderator effects presented here, nor can they explain these moderator effects. Reversed effects indicate that depressed people will experience, or generate, more conflicts than nondepressed people; the moderating effect indicates that a given amount of conflict is more strongly related to impaired well-being among people with more depressive symptoms than among people with fewer depressive symptoms.

Second, various scholars (e.g. Jehn, 1995) have suggested differentiating between two types of conflict, namely relationship conflict (interpersonal disagreement associated with feelings of animosity) and task conflict (disagreement about the best way to solve a problem). Whereas this distinction is common in research on performance, it has been largely ignored in research on well-being and stress (Spector \& Bruk-Lee, 2008). The existing studies, however, have consistently found negative associations between relationship conflict and well-being; the pattern is less clear for task conflict (see Meier et al., 2013). Given that relationship conflict is more strongly related to feelings of rejection than task conflict (e.g. De Dreu, Harinck, \& Van Vianen, 1999), it is possible that the increased vulnerability of people with high levels of depressive symptoms is restricted to relationship conflict. In the current paper, we focused on relationship conflict in the cross-sectional study; in the diary study we used a single item, which does not allow conclusions about the type of conflict. We therefore could not examine the moderating role of depressive symptoms for relationship and task conflict separately, and we suggest such analyses for future research.

Third, the present study did not test the potential mechanism of why people with high levels of depressive symptoms reacted more strongly to conflict. As an example, we postulated that conflicts are threatening the need to belong and therefore are more stressful for individuals with high levels of depressive symptoms because of their insecure feelings of belonging and fears of abandonment. Future research could therefore examine whether the effect of conflict on strain is mediated by a threatened need to belong and how depressive symptoms moderates this indirect relation (i.e. moderated mediation tests). As a second example, we noted that individuals with high levels of depressive symptoms show lower conflict management skills, which may cause conflicts to escalate. Future studies could therefore examine the degree to which the moderating effect of depressive symptoms can be explained by differences in conflict management style (i.e. mediated moderation tests). In general, future research should focus more on the underlying mechanism to inform theory and practice about the increased vulnerability of people with high levels of depressive symptoms.

Finally, both studies used a convenience sample, which imposes limits on generalizability. More specifically, our samples were rather highly educated, which may imply comparatively low reactivity to stressors in general, and to conflicts in particular (see, for instance, Almeida, 2005). Our findings should be replicated using samples more representative of the employed population. 


\section{Conclusions}

Our findings from both a cross-sectional survey and a diary study indicate that chronic depressive symptoms are a vulnerability factor to work stress in the form of interpersonal conflict at work. In line with previous research, both enduring conflicts and daily conflicts were negatively related to both psychological and physical well-being. These effects were particularly strong for employees with impaired psychological resources, namely those with relatively high levels of depressive symptoms. Thus, conflicts may cause depressive symptoms, which in turn make people even more vulnerable to conflicts, indicating a vicious circle with high psychological costs to the individual and economic costs to the organization.

\section{Funding}

This research was supported in part by Grants [PA001-131482] and [PZ00P1-142393] from the Swiss National Science Foundation to Laurenz L. Meier.

\section{References}

Adler, D., McLaughlin, T., Rogers, W., Chang, H., Lapitsky, L., \& Lerner, D. (2006). Job performance deficits due to depression. American Journal of Psychiatry, 163, 1569-1576.

Aiken, L. S., \& West, S. G. (1991). Multiple regression: Testing and interpreting interactions. Newbury Park, CA: Sage.

Almeida, D. (2005). Resilience and vulnerability to daily stressors assessed via diary methods. Current Directions in Psychological Science, 14(2), 64-68.

Baillod, J., \& Semmer, N. (1994). Fluktuation und Berufsverläufe bei Computerfachleuten [Turnover and career paths of computer specialists]. Zeitschrift für Arbeits- und Organisationspsychologie, 38, 152-163.

Baldwin, G., \& Shean, G. D. (2006). A taxometric study of the Center for Epidemiological Studies Depression Scale. Genetic, Social, and General Psychology Monographs, 132, 101-128.

Barrick, M. R., Mount, M. K., \& Judge, T. A. (2001). Personality and performance at the beginning of the new millennium: What do we know and where do we go next? International Journal of Selection and Assessment, 9, 9-30.

Baumeister, R. F., \& Leary, M. R. (1995). The need to belong: Desire for interpersonal attachments as a fundamental human motivation. Psychological Bulletin, 11, 497-529.

Beck, A. T. (1987). Cognitive models of depression. Journal of Cognitive Psychotherapy, 1, 5-37.

Blatt, S., Quinlan, D. M., Chevron, E. S., McDonald, C., \& Zuroff, D. (1982). Dependancy and self-criticism: Psychological dimensions of depression. Journal of Consulting and Clinical Psychology, 50(1), 113-124.

Burke, K. C., Burke, J. D., Regier, D. A., \& Rae, D. S. (1990). Age at the onset of selected mentaldisorders in five community populations. Archives of General Psychiatry, 47, 511-518.

Bolger, N., DeLongis, A., Kessler, R. C., \& Schilling, A. (1989). Effects of daily stress on negative mood. Journal of Personality and Social Psychology, 57, 808-818.

Bonde, J. P. E. (2008). Psychosocial factors at work and risk of depression: A systematic review of the epidemiological evidence. Occupational and Environmental Medicine, 65, 438-445.

Brosschot, J., Gerin, W., \& Thayer, J. (2006). The perseverative cognition hypothesis: A review of worry, prolonged stress-related physiological activation, and health. Journal of Psychosomatic Research, 60(2), 113-124.

Cervone, D. (2005). Personality architecture: Within-person structures and processes. Annual Review of Psychology, 56, 423-452.

Cole, D. A., \& Milstead, M. (1989). Behavioral correlates of depression: Antecedents or consequences? Journal of Counseling Psychology, 36, 408-416.

Coyne, J. C. (1976). Depression and the response of others. Journal of Abnormal Psychology, 85, $186-193$. 
Cummings, J. A., Hayes, A. M., Laurenceau, J.-P., \& Cohen, L. H. (2010). Conflict management mediates the relationship between depressive symptoms and daily negative events: Interpersonal competence and daily stress generation. International Journal of Cognitive Therapy, 3, 318-331.

De Dreu, C., \& Beersma, B. (2005). Conflict in organizations: Beyond effectiveness and performance. European Journal of Work and Organizational Psychology, 14(2), 105-117.

De Dreu, C. K. W., \& Gelfand, M. J. (2008). Conflict in the workplace: Sources, functions, and dynamics across multiple levels of analysis. In C. K. W. De Dreu \& M. J. Gelfand (Eds.), The psychology of conflict and conflict management in organizations (pp. 3-54). New York, NY: Lawrence Erlbaum.

De Dreu, C. K. W., Harinck, F., \& Van Vianen, A. E. M. (1999). Conflict and performance in groups and organizations. In C. L. Cooper \& I. T. Robertson (Eds.), International review of industrial and organizational psychology (Vol. 144, pp. 369-414). Chichester: Wiley.

De Dreu, C. K. W., \& Van de Vliert, E. (1997). Using conflict in organizations. London: Sage.

Diener, E., Oishi, S., \& Lucas, R. E. (2003). Personality, culture, and subjective well-being: Emotional and cognitive evaluations of life. Annual Review of Psychology, 54, 403-425.

Dormann, C., \& Zapf, D. (1999). Social support, social stressors at work, and depressive symptoms: Testing for main and moderating effects with structural equations in a three-wave longitudinal study. Journal of Applied Psychology, 84, 874-884.

Eaton, W. W., Smith, C., Ybarra, M., Muntaner, C., Tien, A. (2004). Center for Epidemiologic Studies Depression Scale: Review and revision (CESD and CESD-R). In M. E. Maruish (Ed.), The use of psychological testing for treatment planning and outcomes assessment: Volume 3 (Instruments for adults) (pp. 363-377). Mahwah, NJ: Erlbaum.

Elfering, A., Grebner, S., Gerber, H., \& Semmer N. K. (2008). Workplace observation of work stressors, catecholamines and musculoskeletal pain among male employees. Scandinavian Journal of Work and Environmental Health, 34, 337-344.

Ellsworth, P. C., \& Scherer, K. R. (2003). Appraisal processes in emotion. In R. J. Davidson, K. R. Scherer, \& H. Hill Goldsmith (Eds.), Handbook of affective sciences (pp. 572-595). Oxford: Oxford University Press.

Finne, L. B., Knardahl, S., \& Lau, B. (2011). Workplace bullying and mental distress - a prospective study of Norwegian employees. Scandinavian Journal of Work and Environmental Health, 37, 276-286.

Folger, J. P., Poole, M. S., \& Stutman, R. K. (2001). Working through conflict: Strategies far relationships, groups and organizations (3rd ed.). New York: Addison, Wesley, Longman.

Forgas, J. P. (1992). Affect in social judgments and decisions: A multiprocess model. In M. P. Zanna (Ed.). Advances in Experimental Social Psychology (Vol. 25, pp. 227-275). New York, NY: Academic Press.

Forgas, J. P. (1994). Sad and guilty? Affective influences on the explanation of conflict in close relationships. Journal of Personality and Social Psychology, 66(1), 56-68.

Forgas, J. (1998). On feeling good and getting your way: Mood effects on negotiator cognition and bargaining strategies. Journal of Personality and Social Psychology, 74(3), 565-577.

Forgas, J. P., Bower, G. H., \& Krantz, S. E. (1984). The influence of mood on perceptions of social interactions. Journal of Experimental Social Psychology, 20, 497-513.

Greenberg, P., Kessler, R., Birnbaum, H., Leong, S., Lowe, S., Berglund, P., \& Corey-Lisle, P. K. (2003). The economic burden of depression in the United States: How did it change between 1990 and 2000? Journal of Clinical Psychiatry, 64, 1465-1475.

Hautzinger, M., \& Bailer, M. (1993). Allgemeine Depressions-Skala (ADS): Manual [Center for Epidemiologic Studies Depression Scale (CES-D): Manual]. Weinheim: Beltz.

Hobfoll, S. E. (2001). The influence of culture, community, and the nested-self in the stress process: Advancing conservation of resources theory. Applied Psychology: An International Review, 50, $337-421$.

Hox, J. (2010). Multilevel analysis. Techniques and applications (2nd ed.). New York, NY: Routledge.

Ilies, R., Johnson, M. D., Judge, T. A., \& Keeney, J. (2011). A within-individual study of interpersonal conflict as a work stressor: Dispositional and situational moderators. Journal of Organizational Behavior, 32(1), 44-64.

Jehn, K. A. (1995). A multimethod examination of the benefits and detriments of intragroup conflict. Administrative Science Quarterly, 40, 256-285. 
John, O. P., \& Gross, J. J. (2004). Healthy and unhealthy emotion regulation: Personality processes, individual differences, and life span development. Journal of Personality, 72, 1301-1334.

Kawakami, N., Araki, S., Kawashima, M., Masumoto, T., \& Hayashi, T. (1997). Effects of workrelated stress reduction on depressive symptoms among Japanese blue-collar workers. Scandinavian Journal of Work, Environment and Health, 23, 54-59.

Kottwitz, M. U., Meier, L. L., Jacobshagen, N., Kälin, W., Elfering, A., Hennig, J., \& Semmer, N. K. (2013). Illegitimate tasks associated with higher cortisol levels among male employees when subjective health is relatively low: An intra-individual analysis. Scandinavian Journal of Work, Environment and Health, 39, 310-318.

Kunin, T. (1955). The construction of a new type of attitude measure. Personnel Psychology, $8,66-77$.

Lang, J., Bliese, P. D., Lang, J. W. B., \& Adler, A. B. (2011). Work gets unfair for the depressed: Cross-lagged relations between organizational justice perceptions and depressive symptoms. Journal of Applied Psychology, 96, 602-618.

Lazarus, R. S. (1991). Emotion and adaption. New York, NY: Oxford University Press.

McTernan, W. P., Dollard, M. F. and LaMontagne, A. D. (2013). Depression in the workplace: An economic cost analysis of depression-related productivity loss attributable to job strain and bullying. Work \& Stress, 27, 321-328.

Meier, L. L., Gross, S., Spector, P. E., \& Semmer, N. K. (2013). Task and relationship conflict at work: Interactive short-term effects on angry mood and somatic complaints. Journal of Occupational Health Psychology, 18, 144-156.

Meurs, J. A., \& Perrewe, P. L. (2011). Cognitive activation theory of stress: An integrative theoretical approach to work stress. Journal of Management, 37, 1043-1066.

Mohr, G. (1986). Die Erfassung psychischer Befindensbeeinsträchtigungen bei Arbeitern [The measurement of mental deterioration of blue-collar workers]. Frankfurt: Peter Lang.

Moulds, M. L., Kandris, E., Starr, S., \& Wong, A. C. M. (2007). The relationship between rumination, avoidance and depression in a non-clinical sample. Behaviour Research and Therapy, 45, 251-261.

Mulders, H. P. G., Meijman, T. F., O’Hanlon, J. F., \& Mulder, G. (1982). Differential psychophysiological reactivity of city bus drivers. Ergonomics, 25, 1003-1011.

Muthén, L. K., \& Muthén, B. O. (2010). Mplus user's guide (6th ed.). Los Angeles, CA: Muthén \& Muthén.

Narayanan, L., Menon, S., \& Spector, P. (1999). Stress in the workplace: A comparison of gender and occupations. Journal of Organizational Behavior, 20(1), 63-73.

Nezlek, J. B. (2007). Multilevel modeling in research on personality. In R. Robins, R. C. Fraley, \& R. Krueger (Eds.), Handbook of research methods in personality psychology (pp. 502-523). New York, NY: Guilford.

Nezlek, J. B., Kowalski, R. M., Leary, M. R., Blevins, T., \& Holgate, S. (1997). Personality moderators of reactions to interpersonal rejection: Depression and trait self-esteem. Personality and Social Psychology Bulletin, 23, 1235-1244.

Nolen-Hoeksema, S. (1990). Sex differences in depression. Stanford, CA: Stanford University Press.

Nolen-Hoeksema, S. (2001). Gender differences in depression. Current Directions in Psychological Science, 10, 173-176.

Nolen-Hoeksema, S., Morrow, J., \& Fredrickson, B. L. (1993). Response styles and the duration of episodes of depressed mood. Journal of Abnormal Psychology, 102, 20-28.

Ohly, S., Sonnentag, S., Niessen, C., \& Zapf, D. (2010). Diary studies in organizational research. An introduction and some practical recommendations. Journal of Personnel Psychology, 9(2), 79-93.

Preacher, K., Curran, P., \& Bauer, D. (2006). Computational tools for probing interactions in multiple linear regression, multilevel modeling, and latent curve analysis. Journal of Educational and Behavioral Statistics, 31, 437-448.

Prisciandaro, J., \& Roberts, J. (2005). A taxometric investigation of unipolar depression in the national comorbidity survey. Journal of Abnormal Psychology, 114, 718-728.

Radloff, L. S. (1977). The CES-D Scale: A self-report depression scale for research in the general population. Applied Psychological Measurement, 1, 385-401.

Raudenbush, S. W., Bryk, A. S., Cheong, Y. K., \& Congdon, R. T., Jr. (2004). HLM 6: Hierarchical linear and nonlinear modeling (Ver. 6.06). Lincolnwood, IL: Scientific Software International. 
Ruscio, J., \& Ruscio, A. (2000). Informing the continuity controversy: A taxometric analysis of depression. Journal of Abnormal Psychology, 109, 473-487.

Schat, A. C. H., Kelloway, E. K., \& Desmarais, S. (2005). The Physical Health Questionnaire (PHQ): Construct validation of a self-report scale of somatic symptoms. Journal of Occupational Health Psychology, 10, 363-381.

Segrin, C. (2000). Social skills deficits associated with depression. Clinical Psychology Review, 20, 379-403.

Spector, P. E., \& Bruk-Lee V. (2008). Conflict, health, and well-being. In C. K. W. De Dreu, \& M. J. Gelfand (Eds.). The psychology of conflict and conflict management in organizations (pp. 267288). San Francisco: Jossey-Bass.

Spector, P. E., \& Jex, S. M. (1998). Development of four self-report measures of job stressors and strain: Interpersonal conflict at work scale, organizational constraints scale, quantitative workload inventory, and physical symptoms inventory. Journal of Occupational Health Psychology, 3, 356-367.

Spector, P. E., Zapf, D., Chen, P. Y., \& Frese, M. (2000). Why negative affectivity should not be controlled in job stress research: don't throw out the baby with the bath water. Journal of Organizational Behavior, 21(1), 79-95.

Stoner, J., \& Perrewé, P. L. (2006). The consequences of depressed mood at work: The influence of supportive supervisors, In A. M. Rossi, P. L. Perrewé, \& S. L. Sauter (Eds.), Current perspectives in occupational stress (pp. 87-99). Greenwich: Information Age.

Teasdale, J. D. (1983). Negative thinking in depression: Cause, effect, or reciprocal relationship? Advances in Behaviour Research and Therapy, 5(1), 3-25.

Tennant, C. (2001). Work-related stress and depressive disorders. Journal of Psychosomatic Research, 51, 697-704.

Van der Klink, J. J. L., Blonk, R. W. B., Schene, A. H., \& Van Dijk, F. J. H. (2001). The benefits of interventions for work-related stress. American Journal of Public Health, 91, 270-271.

Van Katwyk, P. T., Fox, S., Spector, P. E., \& Kelloway, E. K. (2000). Using the Job-Related Affective Well-Being Scale (JAWS) to investigate affective responses to work stressors. Journal of Occupational Health Psychology, 5, 219-230.

Van Lange, P., Otten, W., De Bruin, E., \& Joireman, J. (1997). Development of prosocial, individualistic, and competitive orientations: Theory and preliminary evidence. Journal of Personality and Social Psychology, 73, 733-746.

Warr, P. (1999). Well-being and the workplace. In D. Kahneman, E. Diener, \& N. Schwarz (Eds.), Well-being: The foundations of hedonic psychology (pp. 392-412). New York, NY: Russell Sage Foundation.

Warr, P. (2005). Work, well-being, and mental health. In J. Barling, E. K. Kelloway, \& M. R. Frone (Eds.), Handbook of work stress (pp. 547-574). Thousand Oaks, CA: Sage.

Ylipaavalniemi, J., Kivimäki, M., Elovainio, M., Virtanen, M., Keltikangas-Järvinen, L., \& Vahtera, J. (2005). Psychosocial work characteristics and incidence of newly diagnosed depression: a prospective cohort study of three different models. Social Science \& Medicine, 61(1), 111-122. 